\title{
Aortic root aneurysm: Principles of repair and long-term follow-up
}

\author{
Tirone E. David, MD, Manjula Maganti, MSc, and Susan Armstrong, MSc
}

Objectives: This study was undertaken to examine clinical and echocardiographic outcomes of aortic valve-sparing operations to treat aortic root aneurysms.

\begin{abstract}
Methods: From May 1988 to December 2007, a total of 228 patients underwent reimplantation of the aortic valve, and 61 underwent remodeling of the aortic root. Patients were followed up prospectively and had echocardiographic evaluation of valve function. Mean follow-up was $7.28 \pm 4.33$ years.

Results: There were 5 operative and 26 late deaths. Survival at 12 years was $82.9 \pm 3.7 \%$ and similar between types of operations. Age and aortic dissection were independent predictors of mortality. Seven patients have had reoperations on the aortic valve: 6 for aortic insufficiency and 1 for endocarditis. Five of these patients had undergone remodeling of the aortic root. Freedoms from reoperation at 12 years were $94.3 \% \pm 2.6 \%$ among all patients, $90.4 \% \pm 4.7 \%$ after remodeling, and $97.4 \% \pm 2.2 \%$ after reimplantation $(P=.09)$. Postoperatively, moderate aortic insufficiency developed in 14 patients ( 8 remodeling and 6 reimplantation) and severe aortic insufficiency in 5 ( 3 remodeling and 2 reimplantation). The remaining patients had mild, trace, or no aortic insufficiency. Freedoms from moderate or severe aortic insufficiency at 12 years were $86.8 \% \pm 3.8 \%$ among all patients, $82.6 \% \pm 6.2 \%$ after remodeling, and $91.0 \% \pm 3.8 \%$ after reimplantation $(P=.035)$. Only age - by 5 -year increments - was an independent predictor of postoperative aortic insufficiency.
\end{abstract}

Conclusions: Aortic valve-sparing operations provide excellent patient survival and stable aortic valve function, particularly after reimplantation of the aortic valve. (J Thorac Cardiovasc Surg 2010;140:S14-9)

Aortic valve-sparing operations were developed to preserve the aortic valve in patients with aortic root aneurysm. We coined this term to distinguish these operations from aortic valve repair, ${ }^{1}$ which corrects aortic valve dysfunction largely by addressing abnormalities of the aortic valve cusps. There are basically 2 types of aortic valve- sparing operations: reimplantation of the aortic valve, and remodeling of the aortic root. In patients with a dilated aortic annulus (AA), an aortic annuloplasty with a band of polyester fabric was added to the remodeling of the aortic root, or reimplantation of the aortic valve was used. ${ }^{2}$ During the first decade of experience, we used both techniques without any particular criteria. ${ }^{3}$ During the second decade, we used the reimplantation technique almost exclusively, after learning that the AA could dilate after remodeling of the aortic root and cause aortic insufficiency (AI), ${ }^{4}$ reserving remodeling for older patients with a normal AA. This article summarizes the principles of reconstruction of the aortic root as we have performed it during the past 2 decades and describes the long-term results with these conservative procedures in patients with aortic root aneurysms.

From the Division of Cardiovascular Surgery of Peter Munk Cardiac Centre, Toronto General Hospital and University of Toronto, Toronto, Ontario, Canada.

Disclosures: Tirone E. David is a member of the Speakers Bureau for Medtronic, Inc, St. Jude Medical, and Edwards Lifesciences. Manjula Maganti and Susan Armstrong have nothing to disclose with regard to commercial support.

Received for publication April 27, 2010; accepted for publication July 12, 2010.

Address for reprints: Tirone E. David, MD, 200 Elizabeth St, 4N457, Toronto, Ontario

M5G 2C4, Canada (E-mail: tirone.david@uhn.on.ca).

$0022-5223 / \$ 36.00$

Copyright (c) 2010 by The American Association for Thoracic Surgery doi: $10.1016 /$ j.jtcvs.2010.07.041

\section{PRINCIPLES OF AORTIC ROOT REPAIR}

Isolated dilation of the aortic sinuses does not cause AI. ${ }^{5}$ That is why patients with aortic root aneurysms may have entirely competent aortic valves. As the sinotubular junction (STJ), AA, or both dilate, however, the coaptation area of the cusps decreases, and AI ensues, particularly if the aortic cusps remain normal. Dilation of the STJ, AA, or both is associated with increased mechanical stress on the aortic cusps, which may become thinner and overstretched, developing stress fenestrations in the commissural areas. Depending on the degree of damage, the aortic cusps may not be salvageable. The presence of AI, however, does not preclude aortic valve sparing as long as the tissue that makes up the cusps is of reasonable quality. A mild degree of tissue thinning and cusp prolapse do not appear to preclude a durable repair. ${ }^{6,7}$ On the other hand, an entirely competent aortic valve may have excessively thin and overstretched cusps, which may not be salvageable. Although transesophageal echocardiography remains the best diagnostic tool to determine reparability of the aortic valve, it sometimes underestimates cusp thinning and loss of substance.

Aortic root aneurysms alter the anatomic relationships of the various components of the aortic root (subcommissural triangles, aortic annulus, aortic cusps, aortic sinuses, and STJ). The basic principle of aortic root repair is to correct each anatomic abnormality, which can be quite challenging when all components are abnormal.

\section{Remodeling of the Aortic Root}

Remodeling of the aortic root is a relatively simple operation to treat patients with aortic root aneurysm. This 


\section{Abbreviations and Acronyms \\ $\mathrm{AA}=$ aortic annulus \\ $\mathrm{AI}=$ aortic insufficiency \\ STJ = sinotubular junction}

procedure should be reserved for the older patient with a normal aortic annulus (eg, $\leq 25 \mathrm{~mm}$ for women and $\leq 27 \mathrm{~mm}$ for men). Most of these patients have primarily an ascending aortic aneurysm, and the aortic sinuses become secondarily involved by a degenerative process. Remodeling of the aortic root is performed by excising the aneurysmal aortic sinuses and leaving approximately $5 \mathrm{~mm}$ of aortic wall attached to the annulus. The 3 commissures are pulled upward and approximated until the cusps touch each other centrally, and the diameter of the circle that includes all 3 commissures is probably the ideal diameter of tubular Dacron polyester fabric graft if the cusps are not elongated. Three neoaortic sinuses ( 2 in cases of bicuspid aortic valve) are tailored in one of the ends of the graft. The height of the sinuses should be approximately equal to the diameter of the graft. The width of each neoaortic sinus should be proportional to the intercommissural distance. Next, the 3 commissures are sutured on the outside of the graft, immediately above the neoaortic sinuses. The neoaortic sinuses are sutured to the remnants of the arterial wall and the aortic annulus with continuous 4-0 polypropylene sutures. This suture line must be carefully done, with bites close together to avoid bleeding, a common complication in this operation. We do not use polytetrafluoroethylene felt on this suture line. If the arterial wall is paper-thin, we use 5-0 polypropylene sutures in a fine needle; otherwise, we use a 4-0 polypropylene suture in a fine needle. The coronary arteries are reimplanted in their respective neoaortic sinuses. After that, the cusps are inspected to make sure they are coapting at the same level and well above the nadir of the aortic annulus. If 1 or more cusps are prolapsing, or if they do not lie at least $8 \mathrm{~mm}$ above the level of the nadir of the aortic annulus, the free margin should be shortened by plicating their central portion along the nodule of Arantius. In addition, if a large stress fenestration is present, we routinely reinforce the free margin of the cusp with a double layer of a fine GoreTex suture ${ }^{6}$ (W.L. Gore \& Associates, Flagstaff, Ariz). Clamping of the distal end of the graft and injection of cardioplegia into the reconstructed aortic root is a reliable method to test for valve competence before unclamping of the aorta. Finally, the graft is sutured to the distal ascending aorta, or to the transverse arch graft if it also has been replaced.

\section{Reimplantation of the Aortic Valve}

Reimplantation of the aortic valve addresses every component of the aortic root, which makes it more complicated than remodeling of the aortic root. The aortic root has to be dissected circumferentially down to just below the level of the nadir of the aortic annulus. This is not always possible along the membranous septum, because the right ventricle may be attached a couple of millimeters higher. The aortic sinuses are excised as described previously. Selection of the size of the graft is based largely on the ideal diameter of the STJ, as described previously, with an added 4 to $6 \mathrm{~mm}$. Conversely, the height of the cusps can be used to determine the diameter of the graft. ${ }^{1}$ We also measure the diameter of the AA. A tubular Dacron polyester fabric graft equal in diameter to the ideal STJ plus 4 to $6 \mathrm{~mm}$ is selected. If the diameter of the AA is less than that of the STJ, the graft is plicated to reduce its diameter to that of the AA plus $6 \mathrm{~mm}$ in the areas corresponding to the nadir of the AA. This tailored end of the graft is secured on the outside of the left ventricular outflow tract with multiple (9-12) horizontal mattress sutures. This suture line is scalloped beneath the commissure between right and left cusps and on a plane as horizontal as possible along the fibrous portion. polytetrafluoroethylene felt pledgets are used along the membranous septum and subcommissural triangle between the left and noncoronary cusps, because the tissue is often very thin. We believe that this suture line is crucial in patients with a dilated aortic annulus and that most of the reduction should occur beneath the subcommissural triangles of the noncoronary cusp. The 3 commissures are suspended inside the graft and fixed to the wall with transfixing 4-0 polypropylene sutures with polytetrafluoroethylene felt pledgets.

The spatial relationship of the 3 commissures is very important for proper cusp coaptation. The aortic valve is reimplanted inside the graft by passing the suture from the inside to the outside at the junction between the AA and arterial wall and then from the outside to the inside of the graft by passing through the aortic wall a few millimeters from the AA, creating a crescent shape AA for each cusp. The coronary arteries are reimplanted into their respective neoaortic sinuses. The coaptation level of the cusps is carefully inspected, and appropriate corrections are made as described for remodeling of the aortic root. Darts are placed between each commissure to create bulges in the graft. This maneuver reduces the diameter of the STJ at the rate of $1 \mathrm{~mm}$ for each $3 \mathrm{~mm}$ of plication. Because a graft larger than needed is used, creation of neoaortic sinuses does not cause cusp prolapse. Valve competence and hemostasis along the coronary artery buttons can be assessed by injecting cardioplegia into the graft with the distal end occluded. After that, the graft is sutured to the distal ascending aorta, or transverse arch graft if it also has been replaced. In a small proportion of patients, particularly those with bicuspid aortic valve, a coronary artery orifice may be too close to a commissure to be safely detached and reimplanted. In this case, that coronary artery is left in situ, the graft is incised vertically in that area, and, after the graft has been secured in the annulus, an opening is created and the tissue around the artery is secured to the graft. ${ }^{8}$ 
TABLE 1. Preoperative data

\begin{tabular}{|c|c|c|}
\hline & Reimplantation & Remodeling \\
\hline No. of patients & 228 & 61 \\
\hline \multicolumn{3}{|l|}{ Age (y) } \\
\hline Mean \pm SD & $47.2 \pm 14.9$ & $48.6 \pm 16.0$ \\
\hline Range & $11-79$ & $16-77$ \\
\hline Body surface area $\left(\mathrm{m}^{2}\right.$, mean $\left.\pm \mathrm{SD}\right)$ & $2.04 \pm 0.27$ & $2.07 \pm 0.29$ \\
\hline Sex (no. male) & $181(80 \%)$ & $47(77 \%)$ \\
\hline \multicolumn{3}{|l|}{ Presenting symptoms (no.) } \\
\hline Heart failure & $22(10 \%)$ & $12(20 \%)$ \\
\hline Chest pain & $18(8 \%)$ & $6(10 \%)$ \\
\hline Syncope & 6 & 1 \\
\hline Shock & 2 & 2 \\
\hline \multicolumn{3}{|l|}{ Associated diseases (no.) } \\
\hline Marfan syndrome & $77(34 \%)$ & $26(42 \%)$ \\
\hline Diabetes & 7 & 2 \\
\hline Hypertension & $90(39 \%)$ & $22(36 \%)$ \\
\hline Hyperlipidemia & $47(21 \%)$ & $8(13 \%)$ \\
\hline $\begin{array}{l}\text { Chronic obstructive pulmonary } \\
\text { disease (forced expiratory } \\
\text { volume in } 1 \mathrm{~s}<1 \text { ) }\end{array}$ & 6 & $6(10 \%)$ \\
\hline Previous stroke & 2 & 3 \\
\hline Peripheral vascular disease & 4 & 0 \\
\hline Renal failure on hemodialysis & 6 & 0 \\
\hline Urgent or emergency surgery (no.) & $23(10 \%)$ & $10(16 \%)$ \\
\hline \multicolumn{3}{|c|}{ New York Heart Association functional class (No.) } \\
\hline I & $122(54 \%)$ & $28(46 \%)$ \\
\hline II & $64(28 \%)$ & $20(33 \%)$ \\
\hline III & $16(7 \%)$ & 1 \\
\hline IV & $24(11 \%)$ & 2 \\
\hline Previous heart surgery (no.) & 10 & 5 \\
\hline $\begin{array}{l}\text { Previous replacement of ascending } \\
\text { aorta (no.) }\end{array}$ & 4 & 0 \\
\hline \multicolumn{3}{|l|}{ Cardiac rhythm (no.) } \\
\hline Sinus rhythm & $224(98 \%)$ & $45(90 \%)$ \\
\hline Atrial fibrillation & 4 & $6(10 \%)$ \\
\hline \multicolumn{3}{|l|}{ Left ventricular ejection fraction (no.) } \\
\hline$>40 \%$ & $209(91 \%)$ & $57(95 \%)$ \\
\hline$\leq 40 \%$ & $19(8 \%)$ & 3 \\
\hline Coronary artery disease (no.) & $27(12 \%)$ & $8(12 \%)$ \\
\hline \multicolumn{3}{|l|}{ Aortic valve pathology (no.) } \\
\hline Bicuspid aortic valve & $22(10 \%)$ & 2 \\
\hline \multicolumn{3}{|l|}{ Tricuspid aortic valve } \\
\hline Annuloaortic ectasia & $156(68 \%)$ & $27(44 \%)$ \\
\hline Normal valve and annulus & $50(22 \%)$ & $32(52 \%)$ \\
\hline \multicolumn{3}{|l|}{ Type A aortic dissection (no.) } \\
\hline Acute & $18(8 \%)$ & $7(12 \%)$ \\
\hline Chronic & $10(4 \%)$ & $9(15 \%)$ \\
\hline Arch aneurysm (no.) & $35(15 \%)$ & $21(34 \%)$ \\
\hline Mitral regurgitation (no.) & $17(7 \%)$ & $3(2 \%)$ \\
\hline \multicolumn{3}{|l|}{ Aortic regurgitation (no.) } \\
\hline None or trace & $58(29 \%)$ & $14(26 \%)$ \\
\hline Mild & $39(19 \%)$ & $10(19 \%)$ \\
\hline Moderate & $48(24 \%)$ & $18(34 \%)$ \\
\hline Severe & $55(27 \%)$ & $11(21 \%)$ \\
\hline
\end{tabular}

TABLE 2. Operative data

Reimplantation Remodeling

\begin{tabular}{lcc}
\hline Size of Dacron polyester fabric graft (mm) & & \\
$\quad$ Mean \pm SD & $30.7 \pm 2.8$ & $27.1 \pm 1.9$ \\
$\quad$ Range & $24-34$ & $22-30$ \\
Plication of free margin of aortic cusps (no.) & & \\
$\quad$ cusp & $50(22 \%)$ & $16(26 \%)$ \\
2 cusps & $28(12 \%)$ & 1 \\
$\quad 3$ cusps & $13(5 \%)$ & 2 \\
$\quad$ Reinforcement of free margin with & $51(23 \%)$ & $13(21 \%)$ \\
$\quad$ polytetrafluoroethylene suture (no.) & $103(45 \%)$ & $61(100 \%)$ \\
$\begin{array}{l}\text { Creation of neoaortic sinuses (no.) } \\
\text { Replacement of aortic arch (no.) }\end{array}$ & $35(15 \%)$ & $21(34 \%)$ \\
Mitral valve repair (no.) & $16(7 \%)$ & 3 \\
Mitral valve replacement with & 1 & 0 \\
$\quad$ reconstruction of annulus (no.) & & \\
Repair of abdominal aortic & 1 & 0 \\
$\quad$ aneurysm (no.) & & \\
Maze procedure for atrial fibrillation (no.) & 3 & 0 \\
Aortic clamp time (min, mean \pm SD) & $116 \pm 28$ & $103 \pm 27$ \\
Cardiopulmonary bypass (min, & $140 \pm 34$ & $129 \pm 38$
\end{tabular}

\section{MATERIALS AND METHODS}

From May 1988 to December 2007, a total of 289 consecutive patients underwent aortic valve-sparing operations for aortic root aneurysms. Remodeling of the aortic root was performed in 61 patients, and reimplantation of the aortic valve was performed in 228. Table 1 summarizes the preoperative data of these 2 groups of patients. Table 2 shows the operative data. Patients had annual transthoracic echocardiographic studies to assess aortic valve function, with computed tomographic scan or magnetic resonance imaging of the entire thoracic aorta when appropriate. The follow-up extended from 0 to 20 years, with a mean of $7.28 \pm 4.33$ years $(6.53 \pm 6.28$ for reimplantation and $10.05 \pm 4.39$ years for remodeling, $P<.001$ ).

All statistical analyses were performed with SAS version 9.1 software (SAS Institute, Inc, Cary, NC). Categoric variables are reported as frequencies, and all continuous variables are reported as mean \pm SD. Statistical comparisons between the study groups were tested with the unpaired $t$ test or nonparametric Wilcoxon test for continuous variables and with the $\chi^{2}$ test or Fisher's Exact test for categoric variables. The Kaplan-Meier method was used to calculate estimates for long-term survival or freedom from morbid events. The difference in freedom from AI between the types of aortic valve-sparing operations was evaluated with the log-rank statistic. Age- and sex-matched Ontario general population survival estimates were obtained from the Life Table Template V1.2, a downloadable Excel spreadsheet available at http://www.healthinformation.on.ca. All preoperative variables with a univariate $P$ value of less than .25 or those with known biologic significance despite failing to meet this critical level were submitted to the multivariable model for Cox regression analysis to determine the independent multivariable predictors of late outcomes. Variable retention criteria in the model were set at a $P$ value of .05 .

\section{RESULTS}

There were 5 operative deaths (4 reimplantations and 1 remodeling). The causes of operative death were as follows: myocardial infarction, stroke, low output syndrome, and acute type B aortic dissection and Clostridium difficile colitis. Reexploration of the mediastinum for bleeding or 


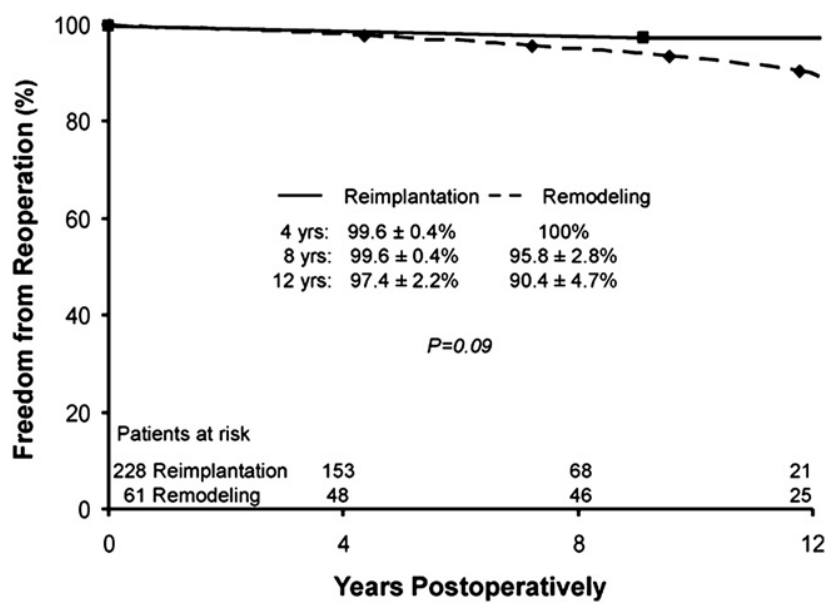

FIGURE 1. Freedom from reoperation on aortic valve according to type of aortic valve-sparing operation.

tamponade was needed in 28 cases. One patient had multiple cardiac arrests soon after arrival in the intensive care unit and was placed back on cardiopulmonary bypass: reexploration of the reconstructed aortic root showed multiple filamentous white thrombi occluding both coronary arteries, with complete disappearance of circulating platelets. This patient survived. Another patient had cardiac arrest and was successfully resuscitated but needed a laparotomy to repair a ruptured right lobe of the liver. This patient survived. The 2 nd patient in the series had persistent AI, and composite replacement of the aortic root with a mechanical valve was performed on the 2 nd postoperative day. This patient survived. Four patients had perioperative myocardial infarctions; 2 needed permanent transvenous pacemaker (both had undergone reimplantation), 2 patients had renal failure and required temporary dialysis, and 1 had a sternal infection. In addition, 54 patients had transient new atrial fibrillation.

There were 26 late deaths: 4 sudden, 4 of complications of aortic dissection, 1 of myocardial infarction, 1 of congestive heart failure, and 16 not cardiovascular related. Survivals at 1 and 12 years were $96.8 \% \pm 1.0 \%$ and $82.9 \% \pm 3.7 \%$, respectively. Although the survival at each interval was slightly higher among patients who had undergone reimplantation than among those who had undergone remodeling, the difference was not statistically significant $(P=.244$ by log-rank). Cox regression analysis identified age by 5 -year increments (hazard ratio, 1.4; $95 \%$ confidence interval, 1.2-1.6; $P<.001)$ and aortic dissection (hazard ratio, 3.2; 95\% confidence interval, 1.3-8.3; $P=.014$ ) as independent predictors of death. The survival of patients without aortic dissection who underwent reimplantation of the aortic valve at the time of surgery was similar to that of the general population matched for age and sex $(91.8 \%$ for reimplantation vs $90.5 \%$ for the general population).

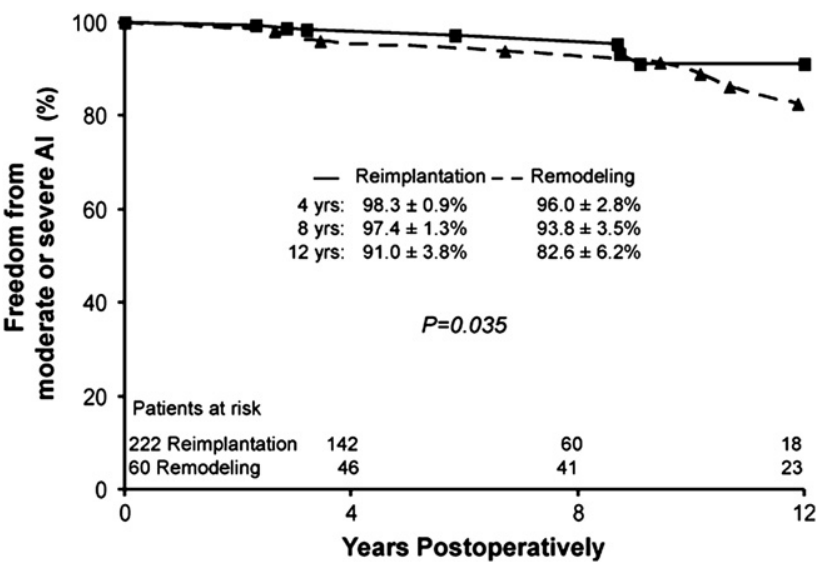

FIGURE 2. Freedom from moderate or severe aortic insufficiency $(A I)$ according to type of aortic valve-sparing operation.

Three patients acquired infective endocarditis: 1 on the aortic valve at 11 years, treated with root replacement with an aortic homograft, and 2 on the mitral valve, 1 treated medically and 1 with mitral valve repair. All patients survived.

Eleven patients had thromboembolic complications: 4 strokes and 7 transient ischemic attacks. All patients with stroke had complete recovery. Twenty-seven patients were receiving oral anticoagulation drugs because of previous thromboembolic complications or atrial fibrillation; 3 of these had major hemorrhagic complications, although none were fatal.

Seven patients required reoperation on the aortic valve: 6 for AI and 1 for infective endocarditis. Five of these patients had undergone remodeling, and 2 had undergone reimplantation. The aortic valve was repaired again in 1 patient and replaced in 6 patients. Freedoms from reoperation on the aortic valve at $4,8,12$ years were $99.7 \% \pm 0.35 \%, 98.4 \% \pm$ $0.96 \%$, and $94.3 \% \pm 2.6 \%$, respectively. Figure $1 \mathrm{com}-$ pares the freedom from reoperation between patients who underwent remodeling versus those who underwent reimplantation. In addition to the reoperations on the aortic valve, 2 patients required mitral valve repair ( 1 at the same time as reoperative aortic valve repair), and 3 patients required replacement of the thoracic or abdominal aorta.

Postoperatively, 14 patients had development of moderate $\mathrm{AI}$ (8 after remodeling and 6 after reimplantation), and $5 \mathrm{pa}-$ tients had development of severe AI ( 3 after remodeling and 2 after reimplantation). The remaining patients have mild, trace, or no AI. Freedoms from moderate or severe AI among all patients at 4,8 , and 12 years were $97.8 \% \pm$ $0.98 \%, 96.4 \% \pm 1.4 \%$, and $86.8 \% \pm 3.8 \%$, respectively. Figure 2 compares the freedoms from moderate or severe AI according to the type of aortic valve-sparing operation. The only independent predictor of AI was age by 5-year increments (hazard ratio, 1.2; 95\% confidence interval, $1.01-1.40 ; P=.034)$. 
At the time of the last follow-up contact, 252 patients were alive and still had their native aortic valves. Of these, 214 were in New York Heart Association functional class I, 33 in class II, and 5 in class III.

\section{DISCUSSION}

In this pioneering series of aortic valve-sparing operations to treat aortic root aneurysm, these operations provided excellent long-term survival, particularly for patients without aortic dissection. Aortic valve function remained stable during the first 12 years of follow-up in most cases. These results are similar to those obtained with mitral valve repair for degenerative disease of the mitral valve. ${ }^{9}$ Only 1 patient left the operating room with moderate to severe AI, and we decided to replace the aortic root on the 2 nd postoperative day. The remaining patients had no more than mild AI at the end of the procedure or at the time of hospital discharge. We paid particular attention to the morphology of the cusps during reconstruction of the root, making sure that they coapted for several millimeters and well above the level of the aortic annulus. Despite this, 19 patients had development of either moderate or severe AI during follow-up. Review of the intraoperative postrepair echocardiograms in those 19 cases did not reveal any clue as to why the valve became incompetent. Of the 19 patients in whom moderate or severe AI developed, 11 had undergone the remodeling procedure, and in 6 cases the AI was believed to be due to progressive dilation of the AA.

Although remodeling of the aortic root is a physiologically superior operation to reimplantation of the aortic valve, ${ }^{10}$ it does not correct the problem of dilation of the aortic annulus that often occurs in young patients with aortic root aneurysm. ${ }^{4}$ Early in our experience, we expressed concerns about this technique, particularly in patients with Marfan syndrome. ${ }^{4}$ Progressive dilation of the aortic annulus after remodeling of the aortic root was the main reason for failure of the procedure. ${ }^{4}$ Other investigators have found similar results. ${ }^{11,12}$ The combination of an aortic annuloplasty with remodeling of the aortic root $^{2}$ did not prevent dilation of the tissues in between in a small group of patients with Marfan syndrome. ${ }^{4}$ After 2 decades of experience with these operations, however, we now believe that remodeling provides excellent results for the older patient with an aortic root aneurysm and a normal aortic annulus. We continue to perform both procedures, and the age of the patient and the diameter of the aortic annulus are the main criteria in choosing the type of operation. It has been shown that the diameter of the aortic annulus is closely related to the patient's body surface area. ${ }^{13}$ For a man with body surface of 2.01 to $2.10 \mathrm{~m}^{2}$, the expected diameter of the aortic annulus is thus $23.0 \pm 1.8$ $\mathrm{mm} .{ }^{7}$ Women have a slightly smaller aortic annulus. Patients with aortic root aneurysms often have larger cusps than normal, with a proportionally larger aortic annulus. An aortic annulus larger than $27 \mathrm{~mm}$ in a man or $25 \mathrm{~mm}$ in a woman probably should be considered dilated, however, even in a large patient with an aortic root aneurysm.

Restoration of normal aortic cusp geometry is the most important technical aspect of aortic valve-sparing operations. Regardless of the technique used, a key to long-term success is the level and area of cusp coaptation. At the end of the procedure, the coaptation of the cusps must therefore be above the level of the nadir of the aortic annulus by a few millimeters, and the length of coaptation must be at least $4 \mathrm{~mm}$ in the central portion.

Several modifications to the 2 original types of aortic valve-sparing operation have been described. ${ }^{14-19}$ The initial outcomes of these newer procedures appear satisfactory, but the long-term results remain unknown. One of the modifications in the reimplantation technique has been the creation of neoaortic sinuses to reduce the velocity of closure of the aortic cusps. This can be done by plication of a cylindric graft, as described here, or by using a commercially available graft with sinuses, the Valsalva Graft (Vascutek Ltd, Inchinnan, UK). We are reluctant to use this graft because its aortic sinuses are spherical, and, at least in theory, this would deform the annulus of each cusp, which evolve along a single horizontal plane. A cylindric graft with neoaortic aortic sinuses that permits reimplantation of the aortic annulus along a single horizontal plane has also been developed in Germany. ${ }^{19}$ Remodeling of the aortic root can be satisfactorily performed with a cylindric graft, and neoaortic sinuses are created by simple tailoring of the graft in the end that is anastomosed to the aortic annulus.

We initially addressed the issue of a dilated annulus during the remodeling procedure by performing an aortic annuloplasty along the fibrous component of the left ventricular outflow tract, because this is the area that dilates. ${ }^{2}$ Recently, a modification of this procedure has been proposed whereby a complete ring is placed on the outside of the left ventricular outflow tract, just beneath the nadir of the aortic annulus. ${ }^{16}$ The investigators of this technique referred to the band as " $\mathrm{ex}$ pandable," but experience with polyester bands in or out of the heart has shown that fibrosis make them rigid with time. More important, however, is the fact that in patients with Marfan syndrome, the native tissue in between the annuloplasty band and the supra-annular graft may dilate with time. ${ }^{4}$

In summary, aortic valve-sparing operations are now part of the armamentarium of surgical options to treat aortic root aneurysms, and the long-term results are excellent, as shown in this study. Reimplantation of the aortic valve into a cylindric graft results in stable aortic valves in most patients during the first 12 years. Remodeling of the aortic root is also an excellent operation for older patients with a normal aortic annulus.

\section{References}

1. David TE, Feindel CM. An aortic valve-sparing operation for patients with aortic incompetence and aneurysm of the ascending aorta. J Thorac Cardiovasc Surg. 1992;103:617-22. 
2. David TE. Remodeling of the aortic root and preservation of the native aortic valve. Op Tech Cardiac Thorac Surg. 1996;1:44-56.

3. David TE, Feindel CM, Bos J. Repair of the aortic valve in patients with aortic insufficiency and aortic root aneurysm. J Thorac Cardiovasc Surg. 1995;109: 345-52.

4. de Oliveira NC, David TE, Ivanov J, Armstrong S, Eriksson MJ, Rakowski H, et al. Results of surgery for aortic root aneurysm in patients with Marfan syndrome. J Thorac Cardiovasc Surg. 2003;125:789-96.

5. Furukawa K, Ohteki H, Cao ZL, Doi K, Narita Y, Minato N, et al. Does dilatation of the sinotubular junction cause aortic insufficiency? Ann Thorac Surg. 1999;68: 949-54.

6. David TE, Armstrong S. Aortic cusp repair with Gore-Tex sutures during aortic valve-sparing operations. J Thorac Cardiovasc Surg. 2010;139:1340-2.

7. David TE, Armstrong S, Maganti M, Colman J, Bradley TJ. Long-term results of aortic valve-sparing operations in patients with Marfan syndrome. J Thorac Cardiovasc Surg. 2009;138:859-64.

8. Sheikh AM, David TE. Aortic valve-sparing operations: dealing with the coronary artery that is too close to the aortic annulus. Ann Thorac Surg. 2009;88: 1026-8.

9. David TE, Ivanov J, Armstrong S, Christie D, Rakowski H. A comparison of outcomes of mitral valve repair for degenerative disease with posterior, anterior, and bileaflet prolapse. J Thorac Cardiovasc Surg. 2005; 130:1242-9.

10. Leyh RG, Schmidtke C, Sievers HH, Yacoub MH. Opening and closing characteristics of the aortic valve after different types of valve-preserving surgery. Circulation. 1999;100:2152-60.

11. Hanke T, Charitos EI, Stierle U, Robinson D, Gorski A, Sievers HH, et al. Factors associated with the development of aortic valve regurgitation over time after two different techniques of valve-sparing aortic root surgery. J Thorac Cardiovasc Surg. 2009;137:314-9.

12. Patel ND, Weiss ES, Alejo DE, Nwakanma LU, Williams JA, Dietz HC, et al Aortic root operations for Marfan syndrome: a comparison of the Bentall and valve-sparing procedures. Ann Thorac Surg. 2008;85:2003-10.

13. Capps SB, Elkins RC, Fronk DM. Body surface area as a predictor of aortic and pulmonary valve diameter. $J$ Thorac Cardiovasc Surg. 2000;119:975-82.

14. Cochran RP, Kunzelman KS, Eddy AC, Hofer BO, Verrier ED. Modified conduit preparation creates a pseudosinus in an aortic valve-sparing procedure for aneurysm of the ascending aorta. J Thorac Cardiovasc Surg. 1995;109: 1049-57.

15. Pacini D, Settepani F, De Paulis R, Loforte A, Nardella S, Ornaghi D, et al. Early results of valve-sparing reimplantation procedure using the Valsalva conduit: a multicenter study. Ann Thorac Surg. 2006;82:865-71.

16. Lansac E, Di Centa I, Raoux F, Bulman-Fleming N, Ranga A, Abed A, et al. An expansible aortic ring for a physiological approach to conservative aortic valve surgery. J Thorac Cardiovasc Surg. 2009;138:718-24.

17. Hess PJ Jr, Harman PK, Klodell CT, Beaver TM, Bologna MT, Mikhail P, et al Early outcomes using the Florida sleeve repair for correction of aortic insufficiency due to root aneurysms. Ann Thorac Surg. 2009;87:1161-8.

18. Pepper J, Golesworthy T, Utley M, Chan J, Ganeshalingam S, Lamperth M, et al. Manufacturing and placing a bespoke support for the Marfan aortic root: description of the method and technical results and status at one year for the first ten patients. Interact Cardiovasc Thorac Surg. 2010;10:360-5.

19. Richardt D, Karluss A, Schmidtke C, Sievers HH, Scharfschwerdt M. A new sinus prosthesis for aortic valve-sparing surgery maintaining the shape of the root at systemic pressure. Ann Thorac Surg. 2010;89:943-6. 